Subscriber access provided by MPI FUR POLYMERFORSCHUNG

Communication

\title{
Persulfurated Coronene: A New Generation of "Sulflower"
}

Renhao Dong, Martin Pfeffermann, Dmitry Skidin, Faxing Wang, Yubin Fu, Akimitsu Narita, Matteo Tommasini, Francesca Moresco, Gianaurelio Cuniberti, Reinhard Berger, Klaus Müllen, and Xinliang Feng

J. Am. Chem. Soc., Just Accepted Manuscript • DOI: 10.1021/jacs.6b12630 • Publication Date (Web): 27 Jan 2017

Downloaded from http://pubs.acs.org on January 30, 2017

\section{Just Accepted}

"Just Accepted" manuscripts have been peer-reviewed and accepted for publication. They are posted online prior to technical editing, formatting for publication and author proofing. The American Chemical Society provides "Just Accepted" as a free service to the research community to expedite the dissemination of scientific material as soon as possible after acceptance. "Just Accepted" manuscripts appear in full in PDF format accompanied by an HTML abstract. "Just Accepted" manuscripts have been fully peer reviewed, but should not be considered the official version of record. They are accessible to all readers and citable by the Digital Object Identifier (DOI®). "Just Accepted" is an optional service offered to authors. Therefore, the "Just Accepted" Web site may not include all articles that will be published in the journal. After a manuscript is technically edited and formatted, it will be removed from the "Just Accepted" Web site and published as an ASAP article. Note that technical editing may introduce minor changes to the manuscript text and/or graphics which could affect content, and all legal disclaimers and ethical guidelines that apply to the journal pertain. ACS cannot be held responsible for errors or consequences arising from the use of information contained in these "Just Accepted" manuscripts. 
Over the last few decades, great efforts have been dedicated to the synthesis of sulfur-rich polycyclic aromatic hydrocarbons (PAHs) ${ }^{1}$, such as acene sulfide, ${ }^{2}$ hexathiotriphenylene, ${ }^{3}$ hexathienocoronene, ${ }^{4}$ sulfur-annelated hexa-peri-hexabenzocoronenes (HBCs), ${ }^{5}$ and sym-tribenzotetrathienocoronenes. ${ }^{6}$ They exhibit unique redox behavior and promising charge transport properties for organic field effect transistors (OFETs) and organic photovoltaics (OPVs). However, fully sulfur-substituted PAHs carrying fused disulfide bonds at the periphery have not yet been achieved. Persulfur-substituted benzene $\left(\mathrm{C}_{6} \mathrm{~S}_{6}\right)$ was reported by Sülzle et al. in 1989 but was only detected as charged fragment during the mass spectrometric investigation of benzo[1,2-d: 3,4-d': 5,6-d"]-tri(1,3-dithiol-2one) after the extrusion of three $\mathrm{CO}$ molecules (Figure 1 left). ${ }^{7}$ In 2006, the appealing structure of octathio[8]circulene $\left(\mathrm{C}_{16} \mathrm{~S}_{8}\right)$, also known as "sulflower" (Figure 1 middle), was reported by Nenajdenko et al. ${ }^{8}$ This molecule can be considered as the first generation of "sulflowers", featuring a $D_{8 \mathrm{~h}}$-symmetrical structure with eight sulfur atoms at the peripheral positions. However, this compound contains one eight-membered central ring fused with eight thiophene units, which possess a rather small $\pi$-delocalized carbon framework. Thereby, the full sulfuration of the periphery of large PAH cores remains a challenge.

Herein, we report the synthesis and characterization of an unprecedented persulfurated coronene $\left(\mathbf{5}, \mathrm{C}_{24} \mathrm{~S}_{12}\right)$ with an all-sulfur terminated edge structure, which we consider as a next-generation "sulflower" (Figure 1 right). The synthesis of compound $\mathbf{5}$ was carried out as depicted in Scheme 1. Starting from coronene (1),

\begin{abstract}
We report the first synthesis of a persulfurated polycyclic aromatic hydrocarbon (PAH) as a next-generation "sul-
flower." In this novel PAH, disulfide units establish an all-sulfur periphery around a coronene core. The structure, electronic properties, and redox behavior were investigated by microscopic, spectro-
scopic and electrochemical methods and supported by density functional theory (DFT). The sulfur-rich character of persulfurated corbatteries, displaying a high capacity of $520 \mathrm{mAh} \mathrm{g}^{-1}$ after $120 \mathrm{cy}-$ cles at $0.6 \mathrm{C}$ with a high-capacity retention of $90 \%$.
\end{abstract}

\section{ACS Paragon Plus Environment}

1,2,3,4,5,6,7,8,9,10,11,12-dodecachlorocoronene $\left(2, \mathrm{C}_{24} \mathrm{Cl}_{12}\right)$ was prepared according to our previous report. ${ }^{9}$ Nucleophilic replacement of all peripheral chloro substituents was achieved using lithium benzylthiolate at room temperature, which afforded $1,2,3,4,5,6,7,8,9,10,11,12$-dodecakis(benzylthio)coronene (3) as a red powder in $62 \%$ yield. After reductive cleavage of the protective benzyl groups under Birch conditions using lithium in anhydrous liquid ammonia at $-78{ }^{\circ} \mathrm{C}$, the dodecalithio coronene1,2,3,4,5,6,7,8,9,10,11,12-dodecathiolate (4) was obtained. The subsequent direct treatment of compound $\mathbf{4}$ with aqueous hydrogen chloride and hydrogen peroxide afforded the desired product $\mathbf{5}$ in $61 \%$ isolated yield over two steps as a dark-red solid after washing in refluxing toluene.

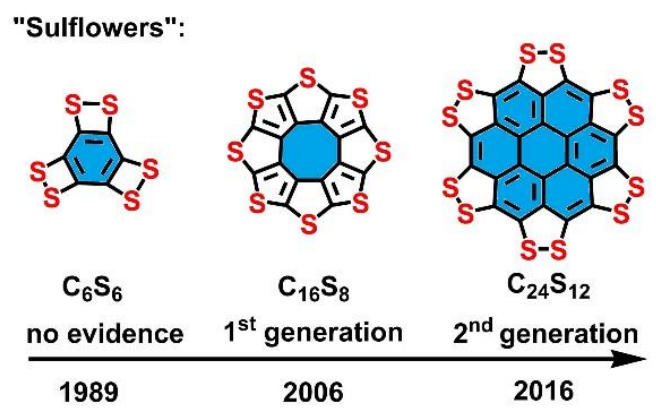

Figure 1. "Sulflower" molecules: (left) persulfurated benzene ( $\left.\mathrm{C}_{6} \mathrm{~S}_{6}\right)$; (middle) fully sulfur-substituted circulene $\left(\mathrm{C}_{16} \mathrm{~S}_{8}\right)$; (right) persulfurated coronene $\left(\mathrm{C}_{24} \mathrm{~S}_{12}\right)$.

The detailed synthetic procedure and characterization data of intermediates are described in Supporting Information (section 1.2). Due to the low solubility of compound $\mathbf{5}$ in common organic solvents, characterization by NMR spectroscopy or growth of single crystals was not possible, even at elevated temperatures. Nevertheless, matrix-assisted laser desorption/ionization time-of-flight mass spectroscopy (MALDI-TOF MS) analysis displayed a clear peak at $m / z=671.6629$, consistent with the expected mass calculated for $\mathrm{C}_{24} \mathrm{~S}_{12}$, i.e., 671.6648 (Figure 2a). The isotopic distribution observed for the obtained PSC sample was in perfect agreement 
with the pattern simulated for chemical formula $\mathrm{C}_{24} \mathrm{~S}_{12}$, corroborating the complete sulfuration (Figure $2 \mathrm{a}$, inset).

Scheme 1. Synthetic Route Towards Persulfurated Coronene $($ PSC, 5) and Perthiolated Coronene (PTC, 6)
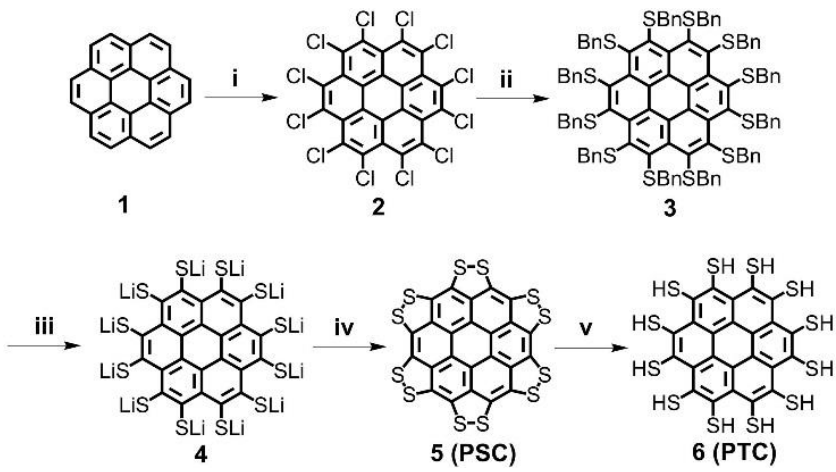

aReagents and conditions: (i) $\mathrm{AlCl}_{3}, \mathrm{ICl}, \mathrm{CCl}_{4}, 81{ }^{\circ} \mathrm{C}, 48 \mathrm{~h}, 93 \%$; (ii) benzyl mercaptan, $\mathrm{NaH}, \mathrm{DMI}, 0{ }^{\circ} \mathrm{C}$ to rt, $16 \mathrm{~h}, 62 \%$; (iii and iv) $\mathrm{Li}$, THF, methanol, $\mathrm{NH}_{3},-78{ }^{\circ} \mathrm{C}$ to rt, $4 \mathrm{~h} ; \mathrm{HCl} / \mathrm{H}_{2} \mathrm{O}_{2} /$ water, rt, $61 \%$; (v) $\mathrm{NaBH}_{4}$
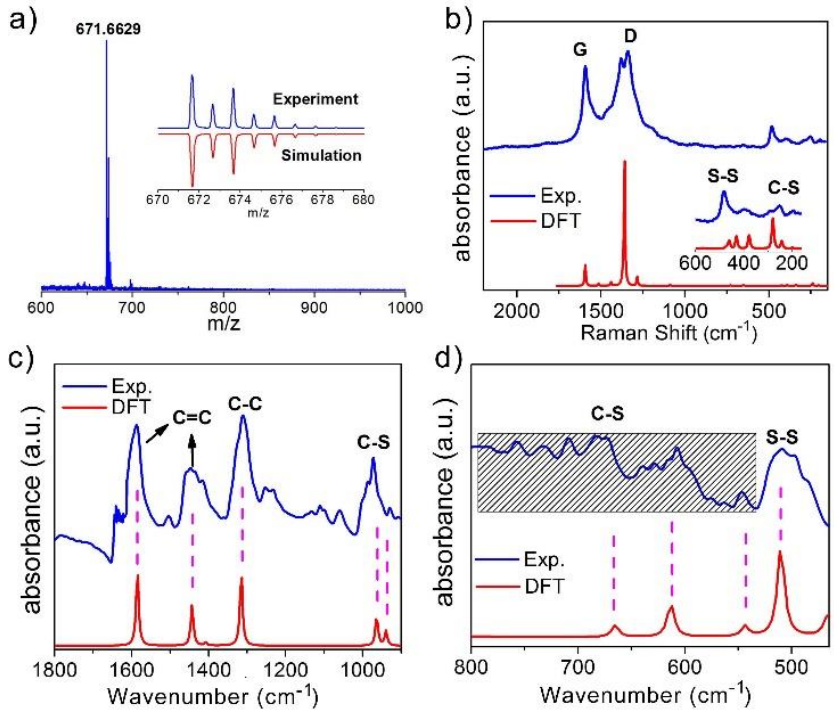

Figure 2. Spectroscopic structure proof of persulfurated coronene (5, PSC). (a) HR-MALDI-TOF MS spectrum. Inset: isotopic distribution compared with the mass spectrum simulated for $\mathrm{C}_{24} \mathrm{~S}_{12}$. (b) Raman spectrum (blue) compared with results from DFT calculations (red) over the $\mathrm{D}$ and $\mathrm{G}$ regions. Inset: the enlarged experimental and calculated curves from $200 \mathrm{~cm}^{-1}$ to $600 \mathrm{~cm}^{-1}$. (c and d) IR spectrum (blue) compared with DFT calculation (red).

To further confirm the structure of $\mathbf{5}$, the compound was characterized by Raman spectroscopy with an excitation wavelength of $532 \mathrm{~nm}$ (Figure 2b). The main expected features of graphene-like molecules were observed for $\mathbf{5}$ (blue line in Figure 2b). A comparison with CVD graphene can be found in Figure S1, namely D $\left(1382 \mathrm{~cm}^{-1}\right)$ and $\mathrm{G}\left(1594 \mathrm{~cm}^{-1}\right)$ bands. ${ }^{10}$ In the low-wavenumber region of the Raman spectrum, weak signals appeared at 256, 392 and $482 \mathrm{~cm}^{-1}$, which are typically assigned to $\mathrm{C}-\mathrm{S}$ bond in plane bending, $\mathrm{C}-\mathrm{S}$ bond deformation and S-S bond from 5, respectively (inset in Figure 2b). ${ }^{11}$ Specific peak assignments are summarized in Table S1 of the Supporting Information. The calculated Raman spectrum is in agreement with the experimental results (red line in Figure $2 \mathrm{~b}$ ). In addition, the IR spectrum of $\mathbf{5}$ was measured and compared with a spectrum calculated by density functional theory (DFT) (Figure 2c and d, Table S2). Although the signals of weak intensity between 545 and $800 \mathrm{~cm}^{-1}$ remain ambiguous for weak C$\mathrm{S}$ absorptions, ${ }^{12}$ a more prominent absorption peak occurred at 971 $\mathrm{cm}^{-1}$ for the C-S stretching vibration. The band at $509 \mathrm{~cm}^{-1}$ is a typical IR absorption for S-S stretching. ${ }^{11 a}$ A weak band at $930 \mathrm{~cm}^{-1}$ (939 $\mathrm{cm}^{-1}$ in DFT-calculated spectrum) reflects the breathing mode of the ring containing the stretching S-S bond. a)

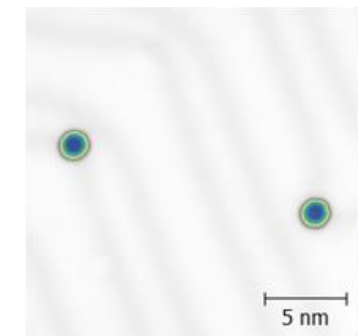

c)

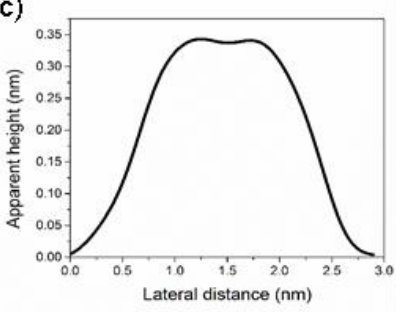

b)

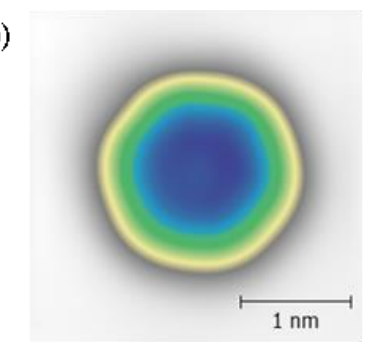

d)

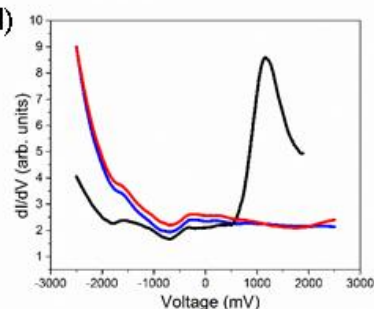

Figure 3. Low-temperature STM characterization of single PSC 5 molecules on the Au (111) surface. (a) STM image showing two PSC 5 molecules adsorbed on an Au (111) terrace at the kink sites ( $\mathrm{I}=20 \mathrm{pA}, \mathrm{U}=0.7 \mathrm{~V})$; (b) STM image of a PSC 5 molecule ( $\mathrm{I}=20$ pA, $\mathrm{U}=0.5 \mathrm{~V})$; (c) Line scan taken along the molecule in (b); (d) $\mathrm{dI} / \mathrm{dV}$ spectra of the molecule in (b): bare Au surface (blue curve), center of the molecule (red curve), edge of the molecule (black curve).

Scanning tunneling microscopy (STM) is a powerful tool for the characterization of single molecules on metal surfaces, thus we performed low-temperature STM studies to visualize compound 5. ${ }^{13}$ Upon adsorption by thermal sublimation, single molecules were present either at the kink sites of the Au (111) herringbone reconstruction (Figure 3a and Figure S2) or at the step edges. The molecules showed a characteristic hexagonal shape, in accord with the six-fold symmetry formed by the outer disulfide bridges (Figure $3 b$ ). According to the line scan in Figure $3 c$, the central core of the molecule was imaged as a depression, and all sulfur atoms formed a homogeneous ring around the core. The observed hexagonal species can be unambiguously assigned to intact $\mathbf{5}$ (Figure $3 \mathrm{~b}$ and Figure S3). The possibility of the desulfuration of $\mathbf{5}$ during sublimation can be excluded (for TGA curves see Figure S4) because full desulfuration would produce pristine coronene, which is known to appear as a uniform, flower-shaped molecule rather than a centrosymmetric molecule on $\mathrm{Au}$ (111), ${ }^{13 \mathrm{~b}}$ whereas partial desulfuration would yield shapes of lower symmetry. Moreover, $\mathrm{dI} / \mathrm{dV}$ spectroscopy measurements were performed on $\mathbf{5}$ (Figure 3d). Although the spectrum obtained over the central part (red curve) simply resembles the spectrum of a bare gold surface (blue curve), there is a clear resonance peak at $1.2 \mathrm{~V}$ in the spectrum obtained over an edge (black curve). The STM measurements thus confirm the full edge sulfuration on coronene for compound $\mathbf{5}$.

Compound $\mathbf{5}$ can be reduced in solution to afford perthiolated coronene (6) via the cleavage of S-S bonds. A suspension of the compound $\mathbf{5}$ was treated with sodium borohydride in DMF under argon protection to obtain $\mathbf{6}$ as a red powder after drying. The PTC 6 exhibits much better solubility in some organic solvents (such as DMF and DMSO) than PSC 5. Characterization by MALDI-TOF 
MS, ${ }^{1} \mathrm{H}$ - and ${ }^{13} \mathrm{C}-\mathrm{NMR}$, and element analysis unambiguously revealed the structure of 6 (see Supporting Information 1.2). Typically, the MALDI-TOF MS analysis displayed an intense signal at $m / z=685.1338$, in agreement with its expected molecular mass calculated for $\mathrm{C}_{24} \mathrm{~S}_{12} \mathrm{H}_{12}$, i.e., 685.1321. The ${ }^{1} \mathrm{H}-\mathrm{NMR}$ spectrum showed only one signal at $\delta=4.11 \mathrm{ppm}$ attributed to the $-\mathrm{SH}$ groups of 6 in deuterated DMSO, which disappeared upon further addition of $\mathrm{D}_{2} \mathrm{O}$, indicating the successful formation of $\mathbf{6}$.
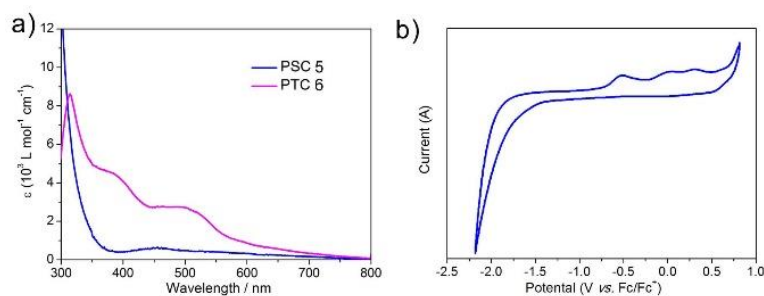

c)
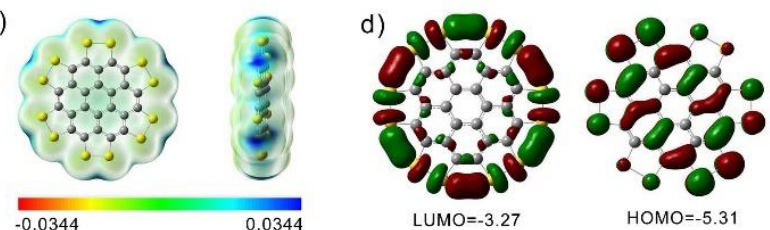

Figure 4. (a) UV/Vis absorption spectrum of PSC 5 (blue) and PTC 6 (pink) in NMP $\left(5 \times 10^{-6} \mathrm{M}\right)$. (b) Cyclic voltammogram of 5 in THF solution of $\mathrm{Bu}_{4} \mathrm{NPF}_{6}(0.1 \mathrm{M})$ with a scan rate of $50 \mathrm{mV} / \mathrm{s}$. (c) Electrostatic potential of 5. (d) Molecular orbitals of 5 by DFT calculation (B3LYP/6-31G (d, p)). Left: LUMO; right: HOMO, the orbital energies are given in $\mathrm{eV}$.

Despite the low solubility of $\mathbf{5}$, its UV/Vis absorption spectrum could be measured in $N$-methyl-2-pyrrolidone (NMP) (Figure 4a), which displayed a weak and broad absorption between 400 and 600 $\mathrm{nm}$. The optical energy gap of $\mathbf{5}$ was determined to be $2.1 \mathrm{eV}$ from the onset of its UV/Vis absorption spectrum (Table S3). In contrast, after reduction by $\mathrm{NaBH}_{4}$, compound 6 showed three pronounced absorption peaks at 314,380 , and $508 \mathrm{~nm}$. The successive reduction could be monitored by studying the UV/Vis absorption spectra as a function of the amount of $\mathrm{NaBH}_{4}$ (Figure S5) and reaction time (Figure S6). The electrochemical properties of 5 were investigated by cyclic voltammetry (CV) in THF solution (Figure 4b). The energy of the highest occupied molecular orbital (HOMO) was estimated from the onset of the first oxidation peak to be $-4.23 \mathrm{eV}$ for 5 (Table S3). The lowest unoccupied molecular orbital (LUMO) energy level was calculated based on the corresponding HOMO level and optical energy gap, as listed in Table S3.

To further investigate the effect of persulfuration on the molecular orbital of the PAHs, DFT calculations were performed at the B3LYP/6-31G (d, p) level (more calculations are shown in SI 6 ). Figure $4 \mathrm{c}$ shows the electrostatic potential of 5 on the 0.002 isodensity surface. Here, the periphery of $\mathbf{5}$ displays electron-donating properties, particularly at the S-S bonds. In addition, the shapes of the HOMO and the LUMO are presented in Figure 4d. Interestingly, the LUMO is not delocalized over the carbon framework but exclusively localized on and in between the sulfur atoms. The HOMO and LUMO energy levels of 5 are -5.31 and $-3.27 \mathrm{eV}$, respectively, yielding a HOMO-LUMO gap of $2.04 \mathrm{eV}$ (Table S3), which is consistent with the optical results.

Its sulfur-rich feature and redox behavior render compound $\mathbf{5}$ a promising active cathode material for lithium-sulfur batteries. In addition, the low solubility of $\mathbf{5}$ in most organic solvents makes it possible to perform continuous charge/discharge cycles. Figure 5a displays the first discharge-charge voltage profiles of $\mathbf{5}$ attained at $0.6 \mathrm{C}(1 \mathrm{C}=1675 \mathrm{~mA} / \mathrm{g})$. The initial discharge/charge capacities were $424 \mathrm{mAh} / \mathrm{g}_{\mathrm{s}}$ and $496 \mathrm{mAh} / \mathrm{g}_{\mathrm{s}}$, leading to an exceptional initial
Coulombic efficiency (ICE) of $85 \%$. Such performance is well comparable with that of reported organic-based matrix/sulfur composites and $\mathrm{S}_{8}$-encapsulated cathodes. ${ }^{11,14,15}$ During the first discharge cycle, the voltage plateau occurred at $\sim 1.8 \mathrm{~V}$, whereas the voltage plateau increased and remained stable at $\sim 2.0 \mathrm{~V}$ over the subsequent cycles (Figure S7). This observation is distinct from what has been typically observed in previously reported cases of $\mathrm{S}_{8}$, in which a two-step discharge plateau is observed: the formation of $\mathrm{Li}$ polysulfide species $\left(\mathrm{Li}_{2} \mathrm{~S}_{\mathrm{n}}, \mathrm{n} \geq 4\right)$ at the first discharge plateau of $2.35 \mathrm{~V}$ and the final product of $\mathrm{Li}_{2} \mathrm{~S}$ at $\sim 2.1 \mathrm{~V}$. ${ }^{14}$ As a result, a one-electron transfer process was proposed to describe the lithiation mechanism along with the formation of LiS complexes and the reforming of disulfides (Figure S8). Moreover, compound 5 exhibited stable cycling performance (Figure 5b). After 120 cycles, a capacity of $520 \mathrm{mAh} / \mathrm{g}$ was retained and $90 \%$ Coulombic efficiency was recorded at $0.6 \mathrm{C}$, revealing the excellent electrochemical performances using the sulfurated PAHs as cathode materials in lithium-sulfur batteries.
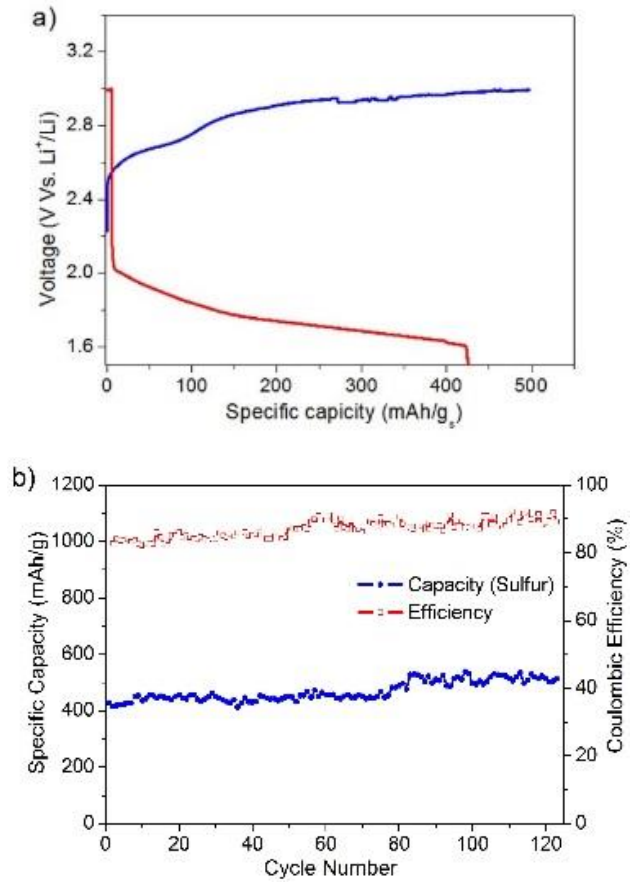

Figure 5. Electrochemical performance of PSC $\mathbf{5}$ molecules as cathode materials of lithium-sulfur batteries. (a) First discharge (red) and charge (blue) curves of PSC measured at $0.6 \mathrm{C}$ in the potential range of 1-3 V vs. $\mathrm{Li} / \mathrm{Li}^{+}$. (b) Capacity (blue) and Coulombic efficiencies (red) versus cycle number for PSC molecules. The blue circles report capacities relative to the weight of the active sulfur species in the cathode.

In summary, we demonstrated a novel synthetic protocol for producing the first fully sulfur-substituted $\mathrm{PAH}$ as a new generation of carbon-sulfur "sulflower" bearing a coronene core. Microscopy and spectroscopy analyses provided explicit proof of the formation of compound $\mathbf{5}$ with a fully disulfide-bond-edged (S-S) structure. Its sulfur-rich character renders $\mathbf{5}$ a promising cathode material for lithium-sulfur battery system. The protocol established in this work offers unique access to larger PAHs and graphene (or graphene nanoribbons) with persulfurated edges and paves the way toward promising applications in OFETs, OPVs, energy, and superconductor-related areas.

\section{ASSOCIATED CONTENT}

\section{Supporting Information}

The Supporting Information is available free of charge on the 
ACS Publications website at DOI:

Experimental details, NMR, MALDI-TOF MS, UV/Vis absorption spectra, STM

\section{AUTHOR INFORMATION}

\section{Corresponding Author}

*muellen@mpip-mainz.mpg.de

*xinliang.feng@tu-dresden.de

\section{Notes}

The authors declare no competing financial interests.

\section{ACKNOWLEDGMENT}

This work was financially supported by the ERC Grant on 2DMATER and EC under Graphene Flagship (No. CNECT-ICT604391). The German Excellence Initiative via the Cluster of Excellence EXC1056 "Center for Advancing Electronics Dresden" (cfaed) and the International Helmholtz Research School Nanonet are gratefully acknowledged. R.H.D. appreciates funding from the Alexander von Humboldt-Foundation. We thank Dr. Yuanzhi Tan, Dr. Ajayakumar Murugan Rathamony, Dr. Junzhi Liu, Dr. Xiaodong Zhuang, Mr. Justus Krüger, and Mr. Frank Eisenhut for the helpful discussion.

\section{REFERENCES}

(1) (a) Narita, A.; Wang, X.; Feng, X.; Müllen, K. Chem. Soc. Rev. 2015, 44, 6616. (b) Stepień, M.; Gońka, E.; Żyła, M.; Sprutta, N. Chem. Rev. 2016, DOI: 10.1021 acs.chemrev.6b00076.

(2) (a) Goodings, E. P.; Mitchard, D. A.; Owen, G. J. Chem. Soc., Perkin Trans. 1 1972, 1310. (b) Nigrey, P. J.; Garito, A. F. J. Chem. Eng. Data 1978, 23, 182. (c) Anthony, J. E. Angew. Chem. Int. Ed. 2008, 47, 452.

(3) (a) Dong, R.; Pfeffermann, M.; Liang, H.; Zheng, Z.; Zhu, X.; Zhang, J.; Feng, X. Angew. Chem., Int. Ed. 2015, 54, 12058. (b) Sakamoto, R.; Kambe, T.; Tsukada, S.; Takada, K.; Hoshiko, K.; Kitagawa, Y.; Okumura, M.; Nishihara, H. Inorg. Chem. 2013, 52, 7411.
(4) Chen, L.; Puniredd, S. R.; Tan, Y.-Z.; Baumgarten, M.; Zschieschang, U.; Enkelmann, V.; Pisula, W.; Feng, X.; Klauk, H.; Müllen, K. J. Am. Chem. Soc. 2012, 134, 17869.

(5) (a) Tan, Y.; Osella, S.; Liu, Y.; Yang, B.; Beljonne, D.; Feng, X.; Müllen, K. Angew. Chem., Int. Ed. 2015, 54, 2927. (b) Cao, J.; Liu, Y. M.; Jing, X.; Yin, J.; Li, J.; Xu, B.; Tan, Y. Z.; Zheng, N. J. Am. Chem. Soc. 2015, 137, 10914.

(6) Zhang, Q.; Peng, H.; Zhang, G.; Lu, Q.; Chang, J.; Dong, Y.; Shi, X.; Wei, J. J. Am. Chem. Soc. 2014, 136, 5057.

(7) (a) Sü1zle, D.; Beye, N.; Fanghänel, E.; Schwarz, H. Chem. Ber. 1989, 122, 2411. (b) Frenking, G. Angew. Chem., Int. Ed. 1990, 12, 1410.

(8) Chernicenko, K. Y.; Sumerin, V. V.; Shpanchenko, R. V.; Balenkova, E. S.; Nenajdenko, V. G. Angew. Chem., Int. Ed. 2006, 45, 7367.

(9) Tan, Y.; Yang, B.; Parvez, K.; Narita, A.; Osella, S.; Beljonne, D.; Feng, X.; Müllen, K. Nat. Commun. 2013, 4, 2646.

(10) Maghsoumi, A.; Brambilla, L.; Castiglioni, C.; Müllen, K.; Tommasini, M. J. Raman Spectrosc. 2015, 46, 757.

(11) (a) Wei, S.; Ma, L.; Hendrickson, K. E.; Tu, Z.; Archer, L. A. J. Am. Chem. Soc. 2015, 137, 12143. (b) Talapaneni, S. N.; Hwang, T. H.; Je, S. H.; Buyukcakir, O.; Choi, J. W.; Coskun, A. Angew. Chem., Int. Ed. 2016 128,3158

(12) Zmolek, P. B.; Sohn, H.; Gantzel, P. K.; Trogler, W. C. J. Am. Chem. Soc. 2001, 123, 1199

(13) (a) Ohmann, R.; Meyer, J.; Nickel, A.; Echeverria, J.; Grisolia, M. Joachim, C.; Moresco, F.; Cuniberti, G. ACS Nano 2015, 9, 8394. (b) Sautet, P.; Joachim, C. Chem. Phys. Lett. 1991, 185, 23. (c) Manzano, C.; Soe, W. H.; Hliwa, M.; Grisolia, M.; Wong, H. S.; Joachim, C. Chem. Phys. Lett. 2013, 587, 35

(14) (a) Ji, X.; Lee, K. T.; Nazar, L. F. Nat. Mater. 2009, 8, 500. (b) Wang, H.; Yang, Y.; Liang, Y.; Robinson, J. T.; Li, Y.; Jackson, A.; Cui, Y.; Dai, H. Nano Lett. 2011, 11, 2644. (c) Bruce, P.; Freunberger, S.; Hardwick, L.; Tarascon, J. Nat. Mater. 2012, 11, 19. (d) Manthiram, A.; Fu, Y.; Chung, S H.; Zu, C. X.; Su, Y. S. Chem. Rev. 2014, 114, 11751.

(15) (a) Yang, Y.; Yu, G.; Cha, J. J.; Wu, H.; Vosgueritchian, M.; Yao, Y.; Bao, Z.; Cui, Y. ACS Nano 2011, 5, 9187. (b) Zhang, C.; Wu, H. B.; Yuan, C.; Guo, Z.; Lou, X. W. Angew. Chem., Int. Ed. 2012, 124, 9730. (c) Jung, D. S.; Hwang, T. H.; Lee, J. H.; Koo, H. Y.; Shakoor, R. A.; Kahraman, R.; Jo, Y. N.; Park, M. S.; Choi, J. W. Nano Lett. 2014, 14, 4418. 


\section{Page 5 of 5}

Journal of the American Chemical Society

1

2

3

4

5

6

7

8

9

10

11

12

13

14

15

16

17

18

19

20

21

22

23

24

25

26

27

28

29

30

31

32

33

34

35

36

37

38

39

40

41

42

43

44

45

46

47

48

49

50

51

52

53

54

55

56

57

58

59

60

TOC

Sulflowers:
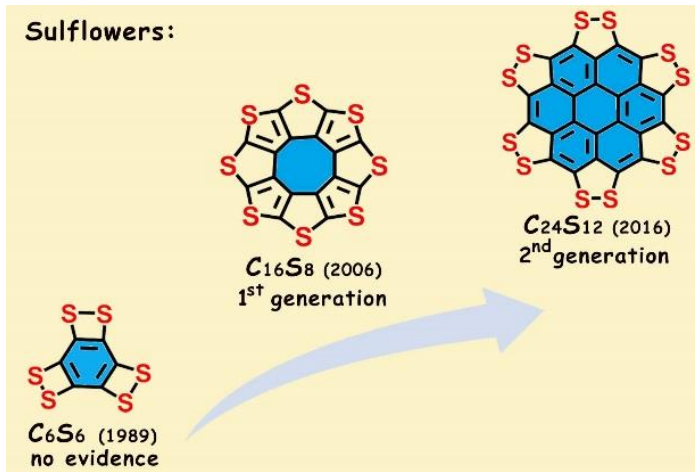